\title{
Obscure bleeding from gastrointestinal metastases of a head and neck squamous cell carcinoma
}

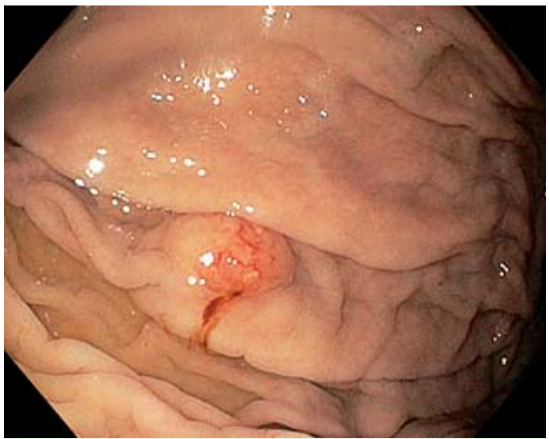

Fig. 1 Endoscopic image showing a gastric metastasis of a head and neck squamous cell carcinoma, which appears as a flat, hypervascular submucosal lesion in the stomach.
A 75-year-old man was referred to our unit for investigation of an iron deficiency anemia. He had been treated with surgery and radiotherapy for a squamous cell carcinoma of the oropharynx 2 years previously. He was receiving ongoing treatment with palliative chemotherapy only for metachronous lung metastases. He had received multiple transfusions because of iron deficiency anemia during the previous 3 months, but upper and lower gastrointestinal endoscopies performed in a private practice unit had been normal. The patient was transferred to our academic hospital so that he could undergo small-bowel capsule endoscopy.

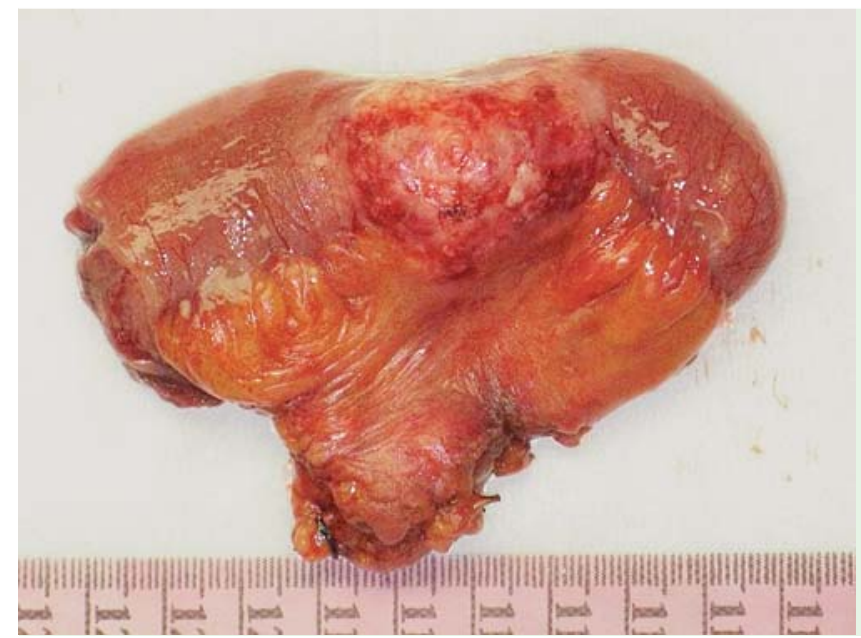

Fig. 2 Gross appearance of the resected small bowel showing a whitish indurated tumor elevating the serosa, with a maximum diameter of $3.5 \mathrm{~cm}$.

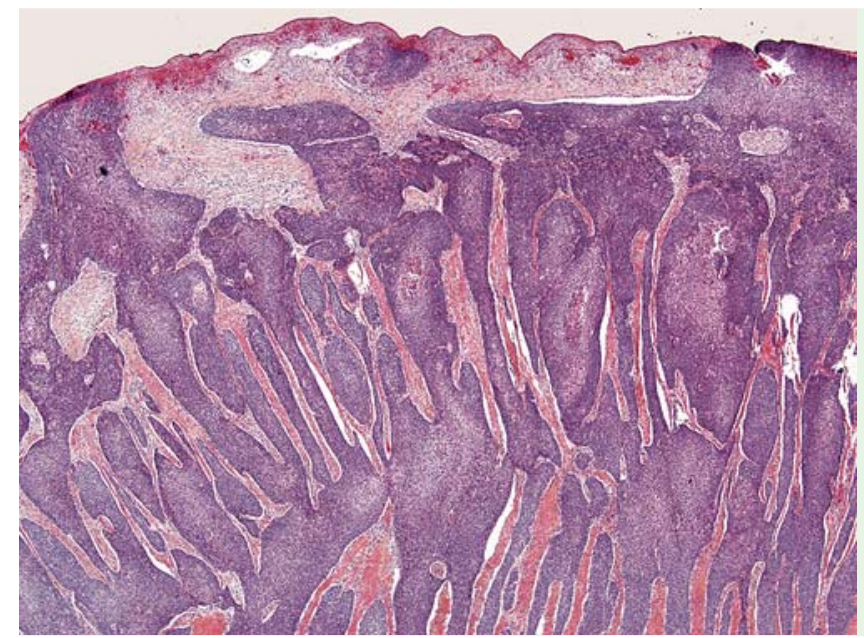

The patient reported one recent episode of melena. On examination he was noted to have a pale appearance and to be tachycardic. He was given a blood transfusion for severe anemia (hemoglobin $6.8 \mathrm{~g} / \mathrm{dL}$ ). Following this we decided that, before proceeding to a small-bowel capsule endoscopy, we would perform a further gastroscopy and colonoscopy. During these procedures two flat, hypervascular submucosal lesions were found in the stomach ( $\bullet$ Fig. 1 ) and one similar lesion was seen in the cecum. Their appearance mimicked flat adenomas but they felt harder to touch with biopsy forceps. Capsule endoscopy identified a bleeding jejunal mass ( $\bullet$ Video 1 ), but unfortunately the capsule stuck above the lesion. The patient underwent emergency surgery, during which a tumor mass was found in the jejunum ( $\bullet$ Fig.2) and a small-bowel resection with anastomosis was performed. Pathological examination showed gastrointestinal metastases from the head and neck squamous cell carcinoma (HNSCC) were present in the jejunum, the stomach, and the colon ( $\bullet$ Fig.3).

Gastrointestinal metastases, in particular in the stomach and colon, are very rare, especially in cases of primary HNSCC. Only 12 reported cases of gastrointestinal metastases of HNSCC were found on PubMed, all of which were small-bowel metastases. This case is, to our knowledge, the first case of diffuse gastrointestinal metastases of an HNSCC involving the stomach and colon, in addition to the small bowel. Life expectancy is reduced [1] because of the already advanced neoplastic disease and in the absence of complications (perforation [2], occlusion, bleeding), noninvasive treatment must be offered.

Gastrointestinal metastases of HNSCC are very rare, but physicians should be aware of the possibility [3]. This unusual case highlights the need for endoscopic investigation of the entire gastrointestinal tract, including the small bowel, in patients with unexplained digestive symptoms and a history of HNSCC, because the discovery of gastrointestinal metastases in such patients will immediately alter their prognosis and their treatment.

\section{Video 1}

Images obtained during small-bowel capsule endoscopy after 90 minutes of recording, showing a bleeding mass obstructing the jejunum. 
Endoscopy_UCTN_Code_CCL_1AC_2AC

Competing interests: None

\section{Jérémie Jacques ${ }^{1}$, Sophie Geyl' ${ }^{1}$, Fabrice Projetti ${ }^{2}$, Paul Carrier ${ }^{1}$, Anne Le-Sidaner ${ }^{1}$, Denis Sautereau ${ }^{1}$, Romain Legros $^{1}$}

${ }^{1}$ Department of Hepatogastroenterology, CHU Dupuytren, Limoges, France

2 Department of Pathology,

CHU Dupuytren, Limoges, France

\section{References}

1 Guillem P, Brygo A, Assila C et al. [Small bowel metastases from head and neck cancers]. Ann Chir 2004; 129: 422-426

2 Aoyagi $Y$, Matsuda K, Shimada $R$ et al. Perforation of the small bowel due to metastasis from tongue cancer. Int Surg 2011; 96 : 90-93

3 Dwivedi RC, Kazi R, Agrawal N et al. Comprehensive review of small bowel metastasis from head and neck squamous cell carcinoma. Oral Oncol 2010; 46: 330 - 335

\section{Bibliography}

DOI http://dx.doi.org/

10.1055/s-0033-1344799

Endoscopy 2014; 46: E18-E19

(c) Georg Thieme Verlag KG

Stuttgart · New York

ISSN 0013-726X

\section{Corresponding author}

Jérémie Jacques, MD

Service d'Hépato-gastro-entérologie

CHU Dupuytren

87042, Limoges

France

Fax: +33-555-058733

jeremiejacques@gmail.com 